\title{
Abordagem do conceito de função no ensino fundamental partindo da aproximação com o cotidiano
}

Arieli dos Santos*, Cleci T. Werner da Rosa**, Marivane de Oliveira Biazus***

\section{Resumo}

O presente estudo tem como objetivo apresentar uma proposta para abordar a introdução e a exploração de alguns conceitos presentes no estudo de funções, em especial as funções do primeiro grau e do segundo grau, no nono ano do ensino fundamental. O trabalho propõe uma sequência de atividades, em que se buscam a contextualização e o uso de ferramentas didáticas, para tornar a aprendizagem matemática mais significativa para o aluno. Como suporte teórico, adotou-se a teoria sociointeracionista, de Vigotski (1999), para estruturar e nortear a elaboração da proposta, bem como a sua implementação em sala de aula. A sequência didática foi estruturada em oito encontros, nos quais o conceito de funções foi abordado utilizando-se o software Tracker, entre outras ferramentas, e implementada em duas turmas de nono ano de uma escola pública do município de Passo Fundo, RS, Brasil.

Palavras-chave: Ensino de funções. Interação social. Tracker.

\section{Introdução}

A matemática é uma ferramenta essencial em várias áreas do conhecimento, por isso sua compreensão entre os estudantes é de extrema importância. No entanto, o que se tem verificado no contexto escolar são dificuldades nos processos de ensinar e aprender, desinteresse, falta de motivação e um alto índice de reprovações na disciplina. Muito se tem discutido a respeito das causas dessas dificuldades enfrentadas pela disciplina entre professores e pesquisadores e, até mesmo, em documentos oficiais (BESSA, 2007; SANCHEZ, 2004; BRUM, 2013; TATTO; SCAPIN, 2004).

É comum os estudantes questionarem em que contexto os conteúdos

\footnotetext{
* Mestranda do Programa de Pós-Graduação em Ensino de Ciências e Matemática, Universidade de Passo Fundo. E-mail: arieli_ssantos@yahoo.com.br

* Doutora em Educação Científica e Tecnológica. Docente do Programa de Pós-Graduação em Ensino de Ciências e Matemática e do Programa de Pós-Graduação em Educação da Universidade de Passo Fundo. Email cwerner@upf.br

*** Doutoranda do Programa de Pós-Graduação em Educação, Universidade de Passo Fundo. E-mail: marivanebiazus@gmail.com
} 
ensinados serão utilizados na vida em sociedade, no trabalho, no comércio, etc. Outro aspecto observado é o número expressivo de estudantes que não gostam da disciplina e têm dificuldade de aprendizado. A forma como a disciplina vem sendo trabalhada acentua o distanciamento entre o aprendizado escolar e as situações cotidianas. Os parâmetros curriculares nacionais (PCNs) reconhecem que a matemática é trabalhada "centrada em procedimentos mecânicos, desprovidos de significados para o aluno" (BRASIL, 1997, p. 15).

Uma mudança de paradigma torna-se necessária. Aulas puramente expositivas, que exigem essencialmente memorização, reprodução e aplicação de regras transmitidas pelo professor, dificultam que o aluno estabeleça relações entre os conteúdos ensinados e o seu cotidiano. Registrar os conteúdos no caderno e reproduzir vários exercícios semelhantes aos exemplos dados pelo professor podem até preparar o aluno para estudos posteriores, mas não garantem que ele se aproprie dos conhecimentos adquiridos para compreender e transformar sua realidade. Por esses motivos, acreditamos que a aprendizagem em matemática está relacionada à compreensão da disciplina. Assim,

[...] o tratamento dos conteúdos em compartimentos estanques e numa rígida sucessão linear deve dar lugar a uma abordagem em que as conexões sejam favorecidas e destacadas (BRASIL, 1997, p. 19).
Ou seja, o conteúdo fará sentido para o aluno a partir do momento em que este conseguir estabelecer relações entre a matemática e as demais disciplinas e entre a Matemática e o seu cotidiano e a partir das conexões que estabelecer entre os diferentes temas matemáticos (BRASIL, 1997).

Tal problemática relacionada ao ensino e à aprendizagem em matemática e frente ao apontado pelos PCNs leva à busca por alternativas didáticas, para qualificar o processo educacional. Nesse contexto, o presente trabalho tem por objetivo apresentar uma alternativa didática para abordar o conceito de funções, recorrendo a situações contextualizadoras e interdisciplinares. O foco está em relatar uma atividade desenvolvida com estudantes do ensino fundamental e desenhada de modo a proporcionar interação entre os estudantes e deles com os materiais e com a professora. Além disso, a atividade foi estruturada de modo a valorizar o contexto no qual esses estudantes estão inseridos.

A sequência didática elaborada é descrita após a apresentação sintetizada da perspectiva teórica que subsidia sua elaboração. A seguir e como continuidade da apresentação da sequência didática, é relatada a aplicação em duas turmas de nono do ensino fundamental. 


\section{Contribuições da teoria sociointeracionista, de Vigotsky, ao ensino da matemática}

Dentro das suas concepções, o professor é quem organiza o saber, para que seja apropriado pelos alunos. Diversas são as possibilidades teóricas de se proceder a essa organização, estando a sua escolha relacionada tanto às propostas educacionais vigentes em documentos oficiais ou escolares quanto às convicções dos docentes. Assim, o presente trabalho elege a perspectiva sociointeracionista para nortear a discussão acerca da construção dos conhecimentos no processo de aprendizagem da matemática.

Inicialmente, é necessário registrar que o ensino de matemática deve proporcionar aos estudantes uma apropriação dos significados dos conceitos, de modo que diferentes relações entre as áreas do conhecimento possam ser estabelecidas, com a perspectiva de compreender os conceitos necessários ao estudo do objeto matemático. A esse respeito, os parâmetros curriculares nacionais sugerem que

[...] a aprendizagem em Matemática está ligada à compreensão, isto é, à apreensão do significado; apreender o significado de um objeto ou acontecimento pressupõe vê-lo em suas relações com outros objetos e acontecimentos. E, o significado da Matemática para o aluno resulta das conexões que ele estabelece entre ela e as demais disciplinas, entre ela e seu cotidiano e das conexões que ele estabelece entre os diferentes temas matemáticos (BRASIL, 1998, p. 56-57).

Ainda, deve-se considerar a escola um espaço privilegiado em que não ocorre exclusivamente a apropriação do conhecimento, mas também a formação do sujeito, enquanto pessoa e cidadão, capaz de intervir em seu meio de forma crítica e ativa. É nesse contexto que as diferentes interações tornam-se a essência e a possibilidade de conhecimento em seu mais amplo significado, permitindo, dessa forma, uma evolução de pensamento dos sujeitos envolvidos.

Nesse sentindo, Vigotsky (1999) considera que a interação ocorre por meio de relações estabelecidas com os contextos social, histórico e cultural no qual o sujeito está imerso. Essas relações são espontâneas, quando ele não tem consciência sobre aquilo que está fazendo, mas, à medida que toma consciência da consciência que possui, mais e mais abstrai sobre seus atos e sobre o meio. Dessa forma, é a partir da interação social entre sujeitos e sujeitos e objetos que os processos de aprendizagem ocorrem e, por consequência, proporcionam 0 aprimoramento das estruturas mentais existentes no sujeito.

No que Vigotsky (1999) denomina de formação de conceitos, ele realiza um confronto entre o conhecimento espontâneo e o científico. De acordo com ele, os conhecimentos (ou conceitos) cien- 
tíficos, diferentemente dos cotidianos, apresentam um sistema hierarquizado, do qual estes fazem parte e pressupõem uma relação consciente e consentida entre sujeito e objeto do conhecimento. A escola representa, segundo esse pensamento, um espaço privilegiado para o aprendizado voltado para a assimilação de fundamentos do conhecimento científico, produzindo "algo novo" do desenvolvimento da criança, além da pura sistematização. Esse "algo novo" está associado à zona de desenvolvimento proximal, outro conceito importante na sua teoria.

A zona de desenvolvimento proximal define as funções que ainda não amadureceram, mas que estão no processo de maturação. Trata-se de uma medida do potencial de aprendizagem, que representa a região na qual o desenvolvimento cognitivo ocorre, ou seja, é dinâmica e está mudando constantemente. Assim, para Vigotsky, as potencialidades do indivíduo devem ser levadas em conta durante o processo de ensino-aprendizagem, porque, no contato com uma pessoa mais experiente e com o quadro histórico-cultural, as potencialidades do aprendiz são transformadas em situações capazes de ativar nele esquemas processuais cognitivos ou comportamentais.

Acredita-se que a interação, a reflexão e o diálogo entre aluno e professor, durante a realização das atividades, podem promover e ampliar sentidos e significados dos conceitos abordados em aula, especialmente em matemática. Nesse sentido, busca-se, na perspectiva sociointeracionista de Vigotsky, referencial para o desenvolvimento de estratégias de ensino, a fim de abordar o conceito de função, o que se apresenta na continuidade.

\section{Sequência didática}

A presente sequência didática para abordar o conceito de função tem por objetivo oportunizar aos professores de matemática uma possibilidade de abordar o tema de forma contextualizada e apoiado em diferentes recursos didáticos. Para tal, parte-se de situações cotidianas e do conceito de movimento de queda livre, conteúdo abordado na disciplina de física, para, então, discutir o conceito de função, especialmente a do primeiro grau e a do segundo grau, abordadas no nono ano do ensino fundamental.

Os encontros foram elaborados dentro da perspectiva sociointeracionista, de Vigotsky, cuja escolha está atrelada à oportunidade que tal teoria oferece em termos de valorização do contexto social no aprendizado e de interação como possibilidade de trocas e de construção do conhecimento. É importante salientar que a sala de aula, por ser um espaço privilegiado para a construção do conhecimento, deve considerar as "bagagens" 
e vivências dos alunos e ser palco de discussões de diferentes saberes.

No Quadro 1, é apresentada a sequência de atividades propostas para abordar o conceito em discussão. Estão previstos oito encontros no total, sendo que cada um corresponde a um período de aula de 45 minutos.

Quadro 1 - Cronograma dos encontros

\begin{tabular}{|l|l|}
\hline Encontro & \multicolumn{1}{|c|}{ Assuntos discutidos } \\
\hline $1^{\circ}$ & $\begin{array}{l}\text { Introdução às primeiras ideias de } \\
\text { funções }\end{array}$ \\
\hline $2^{\circ}$ & Função - o que é? \\
\hline $3^{\circ}$ & Como representar uma função? \\
\hline $4^{\circ}$ & As funções e a física \\
\hline $5^{\circ}$ & Gravação do vídeo \\
\hline $6^{\circ}$ & Analisando os vídeos no Tracker \\
\hline $7^{\circ}$ & $\begin{array}{l}\text { Modelos teóricos das funções do } \\
\text { primeiro grau e do segundo grau }\end{array}$ \\
\hline $8^{\circ}$ & Atividade de encerramento \\
\hline
\end{tabular}

Fonte: autoras.

É importante salientar que as aulas, devidamente estruturadas, representam a oportunidade de que os alunos ampliem (ou reestruturem) seus conhecimentos construídos de forma espontânea, proporcionando um desenvolvimento mental. Tendo como base tais pressupostos, a seguir, é descrito de que forma as aulas podem ser abordadas, tornando-se uma possibilidade de trabalho do professor com os alunos.

\section{Primeiro encontro: introdução às primeiras ideias de funções}

O primeiro encontro aborda as primeiras ideias de funções, com os intuitos de instigar o aluno e propor a identificação do conceito com situações vivenciais. Dessa forma, propõe-se inicialmente apresentar questionamentos, como: "O que é uma equação?", “Que tipos de equações temos?", "O que é uma função?", "Que tipos de funções temos?", "Existe diferença entre equação e função?”, "O que podemos entender por variável?".

Após a discussão inicial, propõe-se assistir ao vídeo Matemática nos transportes (2009), produzido pela TV Escola. $\mathrm{O}$ vídeo tem duração de 25 minutos e aborda os diferentes meios de transporte, como ônibus, táxi e bicicleta, e como a matemática se insere nesse meio. É importante salientar que, na passagem de tempo de $7 \mathrm{~min} 4 \mathrm{~s}$ a $12 \mathrm{~min} 45 \mathrm{~s}$, é apresentado que, em uma corrida de táxi, é possível encontrar uma relação entre o valor pago e a distância percorrida. Tal situação introduz a ideia de uma função do primeiro grau, em que se observam a dependência do valor pago em relação à distância e, ainda, a existência de uma constante, que é o valor da bandeirada. Em outro trecho, que corresponde ao intervalo de $21 \mathrm{~min}$ a $23 \mathrm{~min} 31 \mathrm{~s}$, são abordadas a relação existente entre as 
variáveis que interferem nos custos de uma viagem de ônibus e a sua relação com o valor da passagem paga pelo passageiro.

Após o vídeo, devem ser retomados com os alunos os questionamentos realizados anteriormente, e deve-se fazer uma relação com o que foi observado. Para finalizar o encontro, pode-se propor que os alunos pesquisem quais são os valores pagos na sua cidade por uma corrida de táxi, quanto custa a passagem de ônibus ou, ainda, quais são os custos por quilômetro rodado de um ônibus ou de um carro. O professor pode definir a pesquisa, de acordo com o seu contexto.

\section{Segundo encontro: função - o que é?}

Neste encontro, propõem-se retomar os conceitos e os exemplos abordados pelo vídeo da aula anterior e levantar os dados obtidos da pesquisa realizada pelos alunos, para apresentar o conceito de função. Para isso, pode-se partir do exemplo do preço pago por uma corrida de táxi em função da distância percorrida. No vídeo, é demonstrada a seguinte função: $P=3,5+\left(P_{d} \cdot D\right)$, em que 3,5 é o valor da bandeirada, $P_{d}$ é o preço do quilômetro rodado e D é a distância percorrida. Com os dados apresentados pelos alunos, pode-se reconstruir a função utilizando os dados coletados pelos estudantes.

Pode-se problematizar, colocando para os alunos a seguinte situação: supondo que, no munícipio de Passo Fundo, o valor da bandeirada I seja $\mathrm{R} \$ 4,60$, e o preço pago pelo quilômetro rodado seja $\mathrm{R} \$ 3,50$, quanto pagará um passageiro que andar $1 \mathrm{~km}$ ? E se andar $2 \mathrm{~km}$ ? Reorganizando, teríamos a seguinte função: $P=4,6+3,5 . D$. Partindo-se dessa ideia, propõe-se a construção da Tabela 1 :

Tabela 1 -Valor da passagem em função do quilômetro rodado

\begin{tabular}{|l|c|c|c|c|c|c|c|c|c|c|c|}
\hline Distância percorrida $(\mathrm{km})$ & 0 & 1 & 2 & 3 & 4 & 5 & 6 & 7 & 8 & 9 & 10 \\
\hline Preço $(\mathrm{R} \$)$ & 4,6 & 8,1 & 11,6 & 15,1 & 18,6 & 22,1 & 25,6 & 29,1 & 32,6 & 36,1 & 39,6 \\
\hline
\end{tabular}

Fonte: autoras.

É importante salientar que é possível escolher qualquer valor para a distância percorrida, inclusive valores fracionários ou decimais, como $1,3 \mathrm{~km}$ e 2,5 km, e, para cada um dos valores escolhidos, há somente um preço correspondente a ser pago. Nota-se que os valores para o quilômetro rodado devem ser todos positivos, uma vez que não se pode atribuir valores negativos a esse exemplo específico.

Depois dessa construção e dessa análise, indica-se realizar novos questionamentos: "Como podemos definir uma 
função?”, “O que representam o quilômetro rodado, a distância percorrida e a bandeirada?". Baseando-se nas respostas obtidas, pode-se propor que uma função é a relação de interdependência entre valores de grandezas. A expressão "função de" refere-se, no caso apresentado, à relação entre a grandeza distância percorrida e a grandeza preço, em que o preço a ser pago depende da distância percorrida. Dessa forma, o quilômetro rodado é chamado de variável independente, pois pode ser atribuído um valor qualquer; o preço é a variável dependente, pois depende do valor escolhido para o quilômetro rodado; e a bandeirada é chamada de constante.

\section{Terceiro encontro: como}

\section{representar uma função?}

Este encontro dedica-se a apresentar as diferentes formas de representação de uma função, conforme abordada tradicionalmente pelo livro didático. Fazendo referência ao exemplo trabalhado na aula anterior, deve-se destacar que a tabela construída representa alguns valores possíveis, mas como saber o preço a ser pago para distâncias percorridas que não estão na tabela? Nessa situação, pode-se recorrer à fórmula matemática que representa a relação entre as variáveis analisadas. Essa fórmula matemática, chamada de lei de formação da função, refere-se à expressão analítica. Tradicionalmente, é representada pelas incógni- tas $x$ e $y$, pois formam um par ordenado no plano cartesiano. Tomando como exemplo a função anterior, poderíamos escrever: $y=4,6+3,5 x$, de modo que $y$ é a variável dependente da variável $x$. É importante verificar se os alunos têm conhecimento sobre o plano cartesiano.

Sempre que é atribuído um valor para $x$, e é determinado o seu correspondente $y$, por meio da lei de formação, obtém-se um par ordenado. Com esse par ordenado, pode-se representar a função de forma gráfica. Para representar os dados de uma função, basta marcar os pontos no plano e ligá-los. A representação gráfica do exemplo trabalhado é demonstrada na Figura 1:

Figura 1 - Gráfico do preço em função da distância percorrida

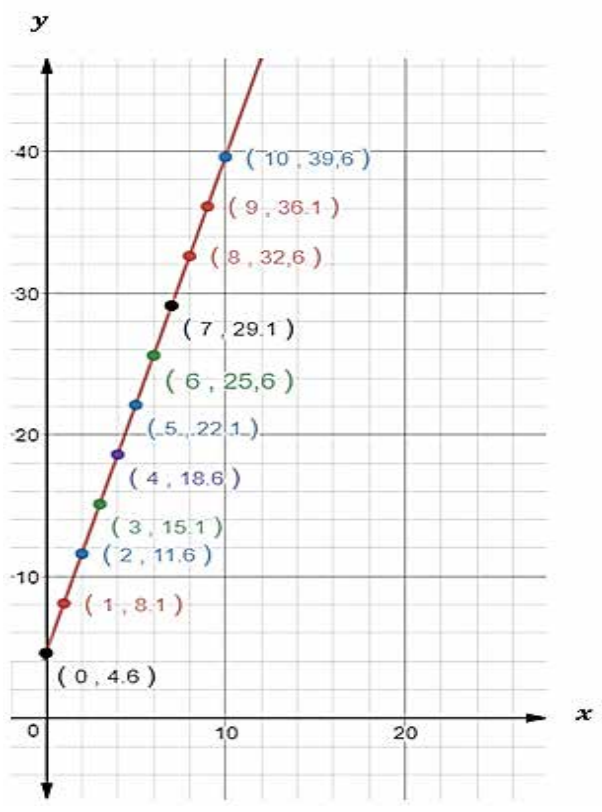

Fonte: autoras. 
É importante destacar para os alunos que o gráfico que representa essa função é uma reta, que está localizada apenas no primeiro quadrante, pois não apresenta valores negativos. Nota-se que o gráfico não inicia na origem, mas no ponto $(0$; 4,6). Considerou-se que, no momento em que o passageiro entrou no táxi, quilômetro 0 , ele já estava pagando $R \$ 4,60$.

Como forma de encerramento da discussão, pode-se instigar os alunos, questionando: “Todas as funções são assim?", "Nunca teremos valores negativos para uma função?”, "Sempre será uma reta a forma de representação de uma função?". Indica-se que os alunos pesquisem a respeito dessas questões e apresentem os resultados de sua busca no encontro seguinte.

\section{Quarto e quinto encontros: as funções e a física}

Para estes encontros, objetivam-se abordar e construir um conhecimento a respeito das funções do primeiro grau e do segundo grau, considerando que, neste momento, os estudantes já têm um conhecimento ampliado em relação ao conceito de função. Partindo da pesquisa proposta pelo professor aos alunos no encontro anterior, deve-se apresentar que há diferentes tipos de funções, e duas, em especial, serão abordadas no nono ano: as funções do primeiro grau e do segundo grau.
Como forma de compreender esses dois tipos importantes de funções, recorre-se à observação de uma situação vinculada à física, com o objetivo de verificar regularidades de um fenômeno físico. Para isso, seleciona-se o evento de queda livre, relacionado ao movimento de um corpo em uma trajetória vertical e sob o efeito do campo gravitacional terrestre. Esse evento, com que estão familiarizados os estudantes, servirá de subsídio para o trabalho das funções mencionadas. Vale lembrar que um corpo em queda livre em que são desprezados os efeitos de resistência do ar realiza um movimento que pode ser analisado a partir das funções do primeiro e do segundo graus, dependendo das variáveis em discussão.

O movimento de um corpo que cai exclusivamente pela ação da força gravitacional é acelerado em função da ação da aceleração gravitacional que denota ao movimento uma variação uniforme na velocidade para intervalos de tempos iguais. Nesse movimento, podem ser estudadas a variação de posição de um corpo ao longo do movimento de queda ou de subida, a variação da velocidade e a aceleração gravitacional que se mantém constante.

A seguir, propõe-se a apresentação de dois vídeos. O primeiro, ${ }^{1}$ "O martelo e a pena - experimento de Galileu na lua", mostra o astronauta Dave Scott, na missão Apolo XV, na Lua, em 1971, reali- 
zando o famoso experimento de Galileu. Nesse experimento, um martelo e uma pena são soltos ao mesmo tempo, e observa-se que ambos chegam à superfície lunar ao mesmo tempo, denotando que a velocidade sofre uma mesma variação. O segundo, ${ }^{2}$ "Experimento de Galileu realizado na maior câmara de vácuo do mundo", mostra o mesmo experimento sendo realizado na maior câmara de vácuo do mundo, onde é possível evidenciar que, sem a resistência do ar, a massa de um objeto não interfere no movimento de queda livre, mas, sim, a altura, o tempo de queda e a aceleração gravitacional do planeta em que o corpo está.

É importante enfatizar que, nesse movimento, a velocidade é alterada no decorrer do tempo, de modo que as variações acontecem de maneira igual para intervalos de tempos iguais. Isso significa que um objeto, quando solto (velocidade inicial igual a zero) na superfície da Terra e desprezando-se a resistência do ar, no primeiro segundo, terá sua velocidade alterada para $10 \mathrm{~m} / \mathrm{s}$. No próximo segundo, passará a $20 \mathrm{~m} / \mathrm{s}$ e assim por diante. Esse aumento na velocidade decorre da aceleração gravitacional ${ }^{3}$ constante, que, no caso da Terra, pode ser representada com certa aproximação pelo valor de $10 \mathrm{~m} / \mathrm{s}^{2}$. Salienta-se que $o$ movimento de queda livre é abordado no ensino de ciências do nono ano, portanto, os alunos já devem ter uma compreensão do fenômeno físico.
Após essa explanação inicial, deve-se propor aos alunos que, organizados em pequenos grupos, façam a gravação de um vídeo sobre a queda de uma bola de sinuca. O vídeo deve ser posteriormente analisado com o auxílio do software Tracker. ${ }^{4}$ Esse software é gratuito; trata-se de uma aplicação gráfica em Java construída na Open Source Physics, em que é possível realizar a análise de diversos tipos de movimento a partir de vídeos. ${ }^{5}$ Salienta-se que esse programa é utilizado tradicionalmente pela física.

\section{Sexto encontro: analisando os vídeos no Tracker}

Este encontro destina-se à análise, no software Tracker, dos vídeos produzidos pelos alunos a respeito do movimento de queda livre de uma bola de sinuca. Como já foi mencionado anteriormente, é possível analisar nesse movimento a variação de posição da bola de sinuca ao longo da queda, a variação da velocidade e a aceleração.

Para a análise dos dados, cada grupo, a partir dos vídeos que foram gravados, deve construir gráficos, e alguns questionamentos devem ser respondidos pelos alunos, conforme são apresentados a seguir. 
Figura 2 - Análise do movimento

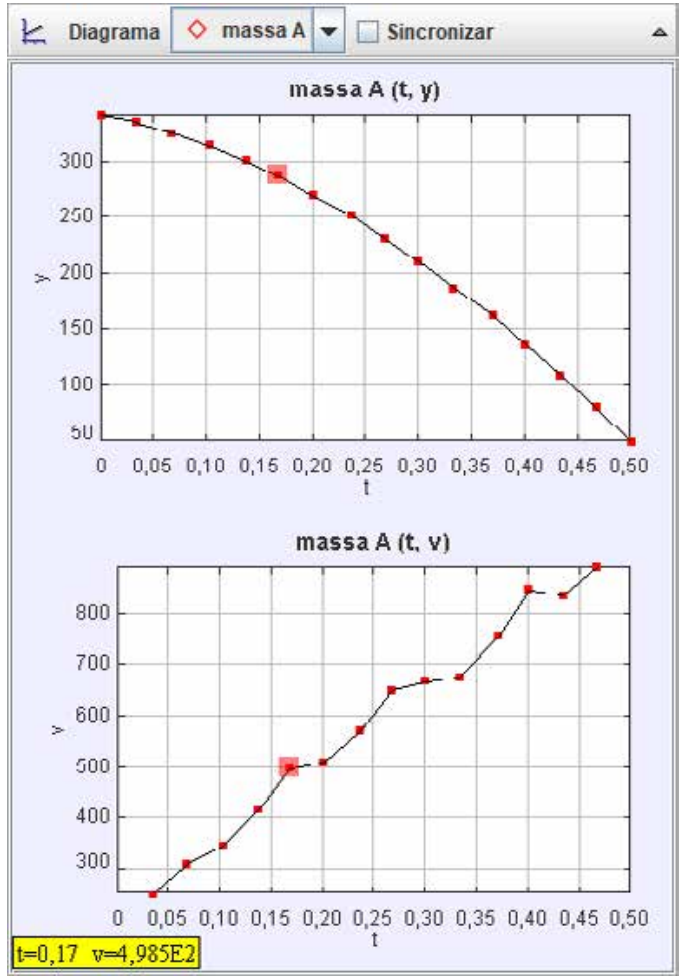

Fonte: autoras.

Questionamentos:

1. A respeito dos gráficos gerados pelo software para a posição, a velocidade e a aceleração, responda:

a) Considerando que o eixo apresentado no vídeo seja do plano cartesiano, o que o eixo $x$ representa em cada gráfico? $\mathrm{E}$ o eixo $y$ ?

b) Quais são as variáveis dependente e independente em cada uma das situações?

c) O gráfico apresenta valores negativos? Justifique a sua resposta.
2. Sobre o gráfico da posição da bola em função do tempo, responda:

a) Qual é a altura inicial da bola? Qual é o intervalo de tempo entre cada uma das posições apresentadas?

b) É possível afirmar que a bola percorre sempre a mesma distância a cada intervalo de tempo? Justifique sua resposta.

c) Os pontos apresentados no gráfico estão alinhados ou não? O gráfico se aproxima a uma curva ou a uma reta?

3. Sobre o gráfico da velocidade da bola em função do tempo, responda:

a) Qual é a velocidade inicial da bola? Qual é o intervalo de tempo entre cada uma das velocidades apresentadas?

b) É possível afirmar que a velocidade da bola em cada intervalo de tempo é a mesma? Justifique sua resposta.

c) Os pontos apresentados no gráfico estão alinhados ou não? O gráfico se aproxima a uma curva ou a uma reta?

Depois de respondido o questionário, os grupos devem socializar as respostas, para que sejam discutidas as análises realizadas. É importante ressaltar que os gráficos representam dados reais do movimento, portanto, a resistência do ar não é desconsiderada, obtendo-se, dessa 
forma, uma aproximação do que seria $o$ modelo teórico. Ressalta-se que o primeiro gráfico representa uma função do segundo grau, e o segundo, uma função do primeiro grau. Podem ser exploradas com os alunos as características percebidas em cada gráfico, como a relação entre as variáveis, alguns pontos do gráfico, a lei de formação, a forma gráfica, entre outros.

\section{Sétimo encontro: modelos teóricos das funções do \\ primeiro e do segundo graus}

O sétimo encontro tem por objetivos sistematizar os conceitos construídos, a partir do movimento analisado no Tracker, e explorar a construção de modelos teóricos, conforme são abordados no livro didático. Julga-se pertinente analisar os seguintes critérios a respeito de uma função: forma, intersecção com os eixos $x$ e $y$, zeros de uma função, eixo de simetria e ponto de vértice da parábola. Existem outros elementos que podem ser explorados, mas eles devem ser abordados no estudo mais aprofundado dessas funções realizado no ensino médio.

Destaca-se que, para construir os gráficos, alguns passos devem ser realizados, como: primeiramente, construir uma tabela atribuindo valores convenientes para $x$ e obtendo seus respectivos valores para $y$; depois, associar cada par ordenado $(x, y)$ obtido na tabela com um ponto no plano cartesiano; e, por fim, marcar a quantidade de pontos suficientes para que seja possível traçar o gráfico. Os valores atribuídos a $x$ é qualquer número real, assim como os alunos puderam verificar no experimento prático. Como exemplo, propõem-se a construção e a análise de dois gráficos, tratando de uma função do primeiro grau e de uma função do segundo grau, conforme é descrito a seguir.

Construção do gráfico da função $y=2 x+2, \operatorname{com} x$ real.

Tabela 2 - Valores atribuídos para $x$ e os respectivos valores obtidos para $y=2 x+2$

\begin{tabular}{|l|c|c|c|c|c|}
\hline$x$ & -2 & -1 & 0 & 1 & 2 \\
\hline$y$ & -2 & 0 & 2 & 4 & 6 \\
\hline
\end{tabular}

Fonte: autoras.

Figura 3 - Gráfico da função dada pela fórmula $y=2 x+2$

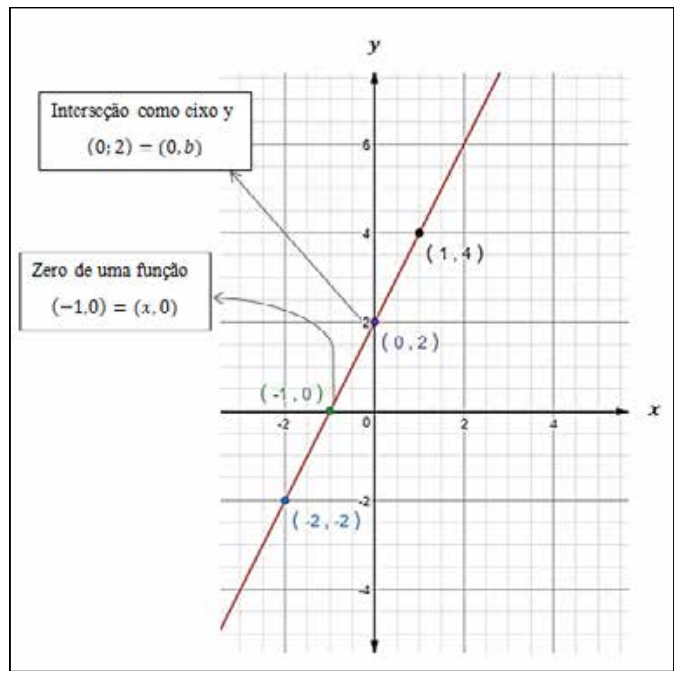

Fonte: autoras 
Acerca do gráfico da função $y=2 x+2$, pode-se considerar que:

- os pontos que representam cada par ordenado foram localizados no plano cartesiano e se encontram alinhados;

- como $x$ pode ser qualquer valor real, existem infinitos pares ordenados;

- os infinitos pares ordenados, ou seja, os infinitos pontos alinhados formam a representação gráfica dessa função, que é uma reta.

Analisando o gráfico anterior, pode-se perceber que a reta intersecta os eixos $x$ e $y$ nos respectivos pontos $(-1,0)$ e $(0,2)$. E, se utilizássemos esses dois pontos apenas, conseguiríamos traçá-la da mesma forma.

$\left.1^{\circ}\right)$ Intersecção com o eixo $y(0, y)$ : o ponto localizado sobre o eixo $y \operatorname{tem} x=0$, ou seja, o ponto em que a reta intersecta o eixo $y$.

Substituindo $x=0$ na lei matemática, obtém-se $y=2$. A reta intersecta $o$ eixo $y$ no ponto $(0,2)$.

$\left.2^{\circ}\right)$ Intersecção com o eixo $x(x, 0)$ : o ponto localizado sobre o eixo $x$ tem $y=0$, ou seja, o ponto em que a reta intersecta o eixo $x$.

Substituindo $y=0$ na lei matemática, obtém-se uma equação do primeiro grau, em que $x=-1$. A reta intersecta $o$ eixo do $x$ no ponto $(-1,0)$. Quando substituímos $y=0$ na lei da função, $o$ valor encontrado para $x$ recebe o nome de zero de uma função.

Funções cuja lei matemática pode ser escrita na forma $y=a x+b$, sendo a e b números reais e a diferente de zero, têm como gráfico uma reta. Esta recebe o nome de função polinomial do primeiro grau, pois o polinômio de maior grau (expoente) encontrado na sua lei matemática é o de grau um.

Construção do gráfico da função $y=x^{2}-2 x-3, \operatorname{com} x$ real.

Tabela 3 - Valores atribuídos para $x$ e os respectivos valores obtidos para $y=x^{2}-2 x-3$

\begin{tabular}{|c|c|c|c|c|c|c|c|}
\hline$x$ & 4 & 3 & 2 & 1 & 0 & -1 & -2 \\
\hline$y$ & 5 & 0 & -3 & -4 & -3 & 0 & 5 \\
\hline
\end{tabular}

Fonte: autoras.

Figura 4 - Gráfico da função

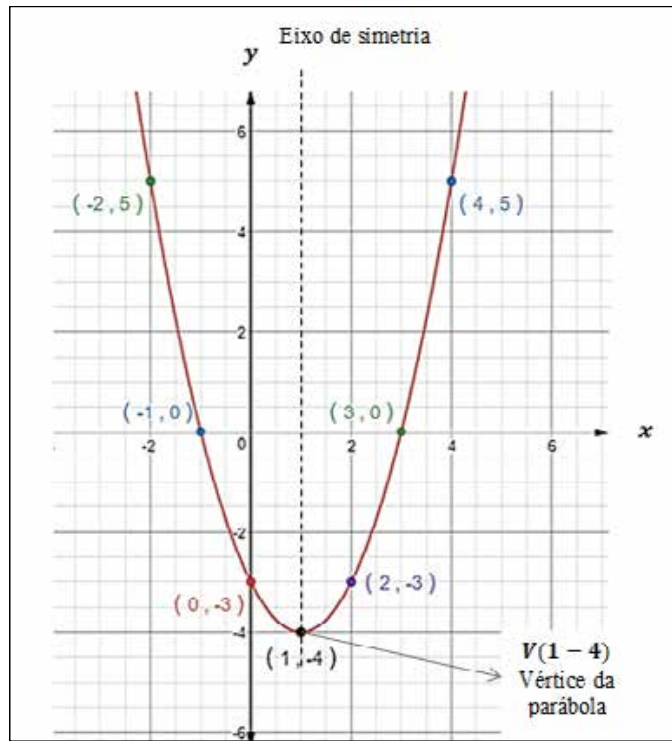

Fonte: autoras. 
Acerca do gráfico da função $y=x^{2}-2 x-3$, pode-se considerar que:

- os pontos não estão alinhados, isso significa que não é uma reta;

- quanto mais valores são atribuídos para $x$, mais pares ordenados são obtidos, e mais fácil é visualizar a forma final do gráfico;

- todos os pares ordenados dessa função formam seu gráfico;

- o gráfico dessa função é uma curva chamada parábola;

- a parábola tem concavidade voltada para cima ("abertura da parábola").

Ao observar o gráfico da função $y=x^{2}-2 x-3$, percebe-se que sua curva apresenta simetria, e o eixo de simetria é perpendicular ao eixo ${ }^{x}$. $O$ vértice é 0 ponto de intersecção do eixo de simetria com a curva. A partir disso, os valores reais de $x$ podem ser definidos depois de encontrada a abscissa do vértice $x_{v}$ pela fórmula $x v=-\frac{b}{2 a}$.

Funções cuja lei matemática pode ser escrita na forma $y=a x^{2}+b x+c$, sendo $a, b$ e $c$ números reais e $a$ diferente de zero, têm como gráfico uma parábola. Esta recebe o nome de função polinomial do segundo grau, pois o polinômio de maior grau (expoente) encontrado na sua lei matemática é o de grau dois.

Pode-se determinar a concavidade da parábola, para cima ou para baixo, por meio do sinal do parâmetro $a$. Se $a>0$, a concavidade será voltada para cima e, se $a>0$ (negativo), a concavidade será voltada para baixo.

Outra forma de construir o gráfico é a partir da escolha de pontos convenientes: o ponto de intersecção da curva com o eixo $y$, os zeros da função e o vértice.

$\left.1^{\circ}\right)$ Intersecção com o eixo $y(0, y)$ : substituindo $x=0$ na lei matemática, obtém-se $y=-3$, o que significa que a parábola intersecta o eixo $y$ no ponto $(0,-3)$.

$\left.2^{\circ}\right)$ Intersecção com o eixo $x(x, 0)$ : substituindo $y=0$ na lei matemática, obtém-se uma equação do segundo grau, cujas raízes são: $x^{\prime}=3$ e $x^{\prime \prime}=-1$. A parábola intersecta o eixo $x$ nos pontos $(3,0)$ e $(-1,0)$. Ao resolver a equação do segundo grau, encontram-se dois zeros para esta função: $x^{\prime}=3$ e $x^{\prime \prime}=-1$.

Estudando o sinal do discriminante $\Delta$, é possível determinar a quantidade de zeros da função do segundo grau. Se $\Delta>0$, a função possui duas raízes reais e diferentes, ou seja, intercepta o eixo do $x$ em dois pontos. Se $\Delta=0$, a função possui duas raízes reais e iguais, ou seja, intersecta o eixo do $x$ em um único ponto. Se $\Delta<0$, a função não possui raízes reais, ou seja, não intersecta o eixo do $x$ em nenhum ponto.

$3^{\circ}$ ) Vértice: quando a função do segundo grau tiver zeros $x^{\prime}$ e $x^{\prime \prime}$, pode-se encontrar a abscissa do vértice $\left(x_{v}\right)$ usando a média aritmética do zeros: $x v=\frac{x^{\prime}+x^{\prime \prime}}{2}$; ou pode-se usar a seguinte fórmula $x v=-\frac{b}{2 a}$. Depois, para en- 
contrar o $y_{v}$, basta substituir o valor encontrado para $x_{v}$ na lei matemática da função. Substituindo $x_{v}=1$, obtém-se $V(1,-4)$.

Após essa explanação, encerra-se o estudo das funções. Salienta-se que outros pontos podem ser destacados pelo professor, conforme for julgado necessário. É interessante propor que, de forma individual e como atividade de casa, os alunos produzam um mapa conceitual sobre o estudo realizado, que poderá ser utilizado na avaliação final do encontro seguinte.

\section{Oitavo encontro: atividade de encerramento}

Como atividade para o último encontro, propõe-se a aplicação de uma avaliação, cujo objetivo é analisar os conceitos construídos pelos alunos ao longo da sequência didática e a forma como relacionam tais conceitos com modelos teóricos. A avaliação pode ser composta por questões presentes no livro didático ou elaboradas pelo professor e deve permitir encontrar indícios da validade ou não das atividades desenvolvidas. Além da avaliação, recomendam-se a análise do mapa conceitual produzido por eles e a avaliação de aspectos referentes à motivação, ao interesse e à interação do aluno com as ferramentas e com o grupo.

\section{Relato da atividade}

A sequência didática descrita foi aplicada com duas turmas de nonos anos, com aproximadamente 35 alunos cada, de uma escola pública estadual do município de Passo Fundo, RS. O desenvolvimento dos encontros seguiu o cronograma das atividades letivas, inclusive os tópicos abordados fizeram parte do plano de trabalho das professoras, que também exerceram o papel de pesquisadoras nessa atividade.

Observou-se que os estudantes, ao realizarem a atividade que exigiu deles um movimento físico e cognitivo, passam a se envolver de forma mais efetiva com o objeto do conhecimento. O uso de ferramentas didáticas assim como a contextualização com situações presentes em outras áreas do conhecimento mostraram-se enriquecedoras, o que foi evidenciado no interesse dos alunos e nos questionamentos levantados durante a realização das atividades.

Cabe salientar que as turmas eram grandes, e havia alunos ingressantes de outras escolas que estavam em fase de adaptação. No geral, os alunos apresentam grandes dificuldades na disciplina de matemática e, por isso, não se identificam e participam pouco ativamente das atividades. Com a aplicação da sequência, conforme mencionado, houve uma participação significativa dos alunos, o que também pôde ser evidenciado na 
avaliação pela melhora no rendimento de grande parte dos alunos. Contudo, destaca-se que nem todos os alunos se envolveram e realizaram as tarefas propostas, revelando a necessidade de se avaliar e refletir de forma mais aprofundada o desenvolvimento das atividades e, também, a aplicação em outros contextos.

\section{Consideraçōes finais}

Diante dos vários desafios enfrentados no cenário atual da educação e do ensino de matemática, falta de motivação, número significativo de estudantes que dizem não gostar dessa disciplina, dificuldades tanto no processo de ensinar quanto no de aprender e ensino centrado em procedimento mecânicos e descontextualizado de situações reais acabam acentuando o distanciamento entre os conhecimentos que serão utilizados na vida e aqueles aprendidos na escola. A realização das práticas citadas mostrou ser possível abordar o conceito de funções recorrendo a situações contextualizadoras e interdisciplinares, objetivando proporcionar interação entre os estudantes e deles com os materiais e com a professora.

A sequência didática apresentada buscou abordar o conceito de função no ensino fundamental de forma a explorar situações envolvendo a física, visando a uma aproximação entre tais conceitos e o cotidiano do aluno. A atividade bus- cou também proporcionar um primeiro contato com as funções do primeiro e do segundo graus e suas respectivas representações gráficas a partir de situações vivenciadas e experienciadas pelos alunos.

Considerando as atividades propostas ao longo desta sequência didática, é possível afirmar que os estudantes do nono ano se envolveram e demostraram interesse pelo trabalho, bem como mostraram compreender melhor o conceito de função, o que valida a sequência didática. Mesmo reconhecendo a validade do que foi realizado, tem-se consciência de que a sequência didática não está pronta, e há necessidade de se realizar outras aplicações, pois o conhecimento é dinâmico.

\section{Approach to the concept of function in elementary school from the approximation with the daily}

\section{Abstract}

The present study aims to present a proposal to address the introduction and exploration of some concepts present in the study of functions, especially the function of the first degree and the second degree, in the ninth year of elementary school. The work proposes a sequence of activities, in which contextualization and the use of didactic tools are sought, to make mathematical learning more meaningful for the student. As a theoretical support, the socio-interactionist 
theory of Vigotsky (1999) was adopted to structure and guide its elaboration, as well as the implementation in the classroom. The didactic sequence was structured in eight meetings, in which the concept of functions was approached, using Tracker software among other tools, and implemented with two ninth classes from a public school in the city of Passo Fundo, RS, Brazil.

Keywords: Teaching functions. Social interaction. Tracker.

\section{Notas}

1 O vídeo pode ser acessado no endereço: <https:// www.youtube.com/watch?v=HqcCpwIeiu4>.

2 Ovídeo pode ser acessado no endereço: $<$ https://www. youtube.com/watch?v=qSeW0f51QzY\&t=19s $>$.

3 Aceleração da gravidade é a intensidade do campo gravitacional em um determinado ponto, portanto, os valores variam dependendo da altitude e da latitude do local.

4 Pode-se fazer download do software no endereço: $<$ https://physlets.org/tracker/>.

5 Para ter acesso a recomendações sobre a instalação do software, sugere-se o endereço: <http:// trackernoensinodafisica.blogspot.com>.

\section{Referências}

BESSA, K. P. Dificuldades de aprendizagem em matemática na percepção de professores $e$ alunos do ensino fundamental. Brasília: Universidade Católica de Brasília, 2007. Disponível em: <http://www.ucb.br/sites/100/103/ TCC/22007/ KarinaPetriBessa.pdf $>$. Acesso em: 11 ago. 2018.

BRASIL. Secretaria de Educação Fundamental. Parâmetros Curriculares Nacionais: matemática. Brasília: MEC/SEF, 1997.

BRUM, W. P. Crise no ensino de matemática: amplificadores que potencializam o fracasso da aprendizagem. São Paulo: Clube dos Autores, 2013.
MATEMÁTICA em toda parte: matemática nos transportes. Produção de TV Escola. [S. l.]: Aiupa Produções e Muzarca Produções e Editora, 2009. On-line. Disponível em: <https:// api.tvescola.org.br/tve/video/matematica-em-toda-parte-matematica-nos-transportes $>$. Acesso em: 25 out. 2018 .

SANCHEZ, J. N. G. Dificuldades de Aprendizagem e Intervenção Psicopedagógica. Porto Alegre: Artmed, 2004.

TATTO, F.; SCAPIN, I. J. Matemática: por que o nível elevado de rejeição? Revista de Ciências Humanas, v. 5, n. 5, p. 1-14, 2004.

VIGOTSKI, L. S. A formação social da mente: o desenvolvimento dos processos psicológicos superiores. Tradução de José Cipolla Netto et al. 6. ed. São Paulo: Martins Fontes, 1999. 